\title{
The Possibility of Increasing the Achromatic Tone Values of FOGRA 51 Standards Achieved by the Modification of in Line Pre-Treatment of the Printing Substrate
}

\author{
Marko MORIĆ, Igor MAJNARIĆ, Damir MODRIĆ
}

\begin{abstract}
For high-quality black \& white printing realized with an electrophotography printing machine, it is necessary to prepare the printing substrate. For optimal adhesion of the black liquid electrophotography ink to the printing substrate, it is necessary to apply additional treatment to meet ideal substrate surface tension by means of corona treatment and/or coating with fluid for regulating the surface tension (primer). This paper examines the influence of the corona power and the thickness of used fluid for the regulation of surface tension on the achromatic digital reproduction quality. Within the electrophotography printing process, this implies determining the differences in the colour gamut volume, the structure of characteristic screening elements, the amplitude-modulated screening, and the increase in the number of colour separations. The results show that the optimal colour tone values, colour gamut, and dot gain, high quality of digital prints will be realized without the use of the fluid for the regulation of surface tension and without activation of the corona power. That confirms that the FOGRA values for industrial standards can be used for quality electrophotography printing.
\end{abstract}

Keywords: corona treatment; Electrolnk; FOGRA PSD; HP Indigo; surface tension regulating fluid

\section{INTRODUCTION}

Digital printing techniques are increasingly represented in the process of producing graphics products. Especially the principles of inkjet printing and electrophotography digital printing are emphasized [1]. Because of the low viscosity ink and for the purpose of performing complex graphics products (labels on coated paper), consideration should also be given to printing preprocessing parameters. They change surface properties, and thus the "printability" itself. To achieve the ideal adhesion of the inks on a paper-based substrate, the HP Indigo narrow web printing machines use additional in-line corona and primer units.

Printing with new generations of digital printing technologies is extremely complex and has been studied in several doctoral dissertations of the Rochester Institute of Technology where quality and economic costeffectiveness correlation was studied [2]. In all these studies were used standard (IT8.7-4) and special test forms which contain line and dot microelements [3]. The novel procedure for multicolour reproduction monitoring has been issued by the German printing association (for fine art paper - FOGRA 51) [4], while the G7 method applies to the US print media market [5]. To achieve a large volume of gamut, it is necessary to apply Hexachrome printing, with the addition of orange and green ink to achieve higher colour quality $[6,7]$. In this case, it is necessary to apply a special stochastic screening whose algorithms ensure acceptable noise reduction [8].

The aim of this study was to examine the quality of black \& white $(\mathrm{B} \& \mathrm{~W})$ reproduction by applying additional pre-treatment (corona and/or primer) of printing substrate by means of colorimetric methods and compare them to the existing FOGRA PSD standard [9]. This will provide new recommendations for high-quality tone reproduction by optimizing the in-line printing substrate surface pretreatment as well as by controlling the amount of the corona power. We expect that this treatment will increase the quality of digital $\mathrm{B} \& \mathrm{~W}$ reproduction with unstable black liquid electrophotography ink. The printing substrate properties were not subject of this study.

\section{THEORETICAL PART}

Electrophotography as a printing method applies two types of inks (powder and conductive liquid toners). All of the HP Indigo printing machines, that have been presented to the market over the last 20 years, generally use indirect printing principle, a digital colour offset that is carried out in six phases: charging roller, imaging with ROS laser head, photoreceptor development, first transfer, second transfer, photoreceptor cleaning and preparation for the next print cycle [10].

\subsection{Digital Colour Offset}

The development and improvement of such printing technology were accomplished by numerous scientists whose papers were published in relevant journals. Thus P. Forgacs worked on HP Indigo machine ink transfer issues, such as ink adhesion and separation of solid bodies [11].

The previous $\mathrm{A} 3+$ format printing machine constructions were improved with increased production speed $(60 \mathrm{~m} / \mathrm{min}$ for the printing of one colour separation). For the printing market needs, there is also a B2 format machine configuration $(700 \times 500 \mathrm{~mm})$. Consequently, there was a change in dimensions of PIP (Photo Image Plate), Laser Writing Heads, Ink System BID's (Binary Ink Development) and paper transport device [12]. Because of the satellite machine construction, it is possible to print with additional inks (CMYK + PANTONE) [13]. This generation of machines also have the possibility of in-line scanner to perform automatic print quality control based on image analysis. To create a single print, the machine construction demands three cylinders (PIP, Intermediate Transfer and Impression) to transfer the ElectroInk to the printing substrate (Fig. 1).

ElectroInk is an especially liquid electrophotography ink that contains the following components: volatile ISOPAR oil $(90 \%$ to $95 \%)$, pigments $(5 \%$ to $8 \%)$ and charge regulation liquid (Image agent) (1\% to $3 \%)$. The preparation of such ElectroInk is carried out immediately prior to printing, using density meters (dry matter content measurements) whose value must be exactly $1.70 \mathrm{~g} / \mathrm{cm}^{3}$ $[14,15]$. The selective behaviour of ElectroInk depends on 
the established electrostatic field between developer roller and PIP cylinder, and between PIP and Intermediate Transfer cylinder [16, 17].

Due to indirect printing, the liquid ElectroInk is transferred to the heated surface of the Intermediate Transfer cylinder which is functionally covered with soft offset rubber. During this process ElectroInk changes the aggregate state and transfers into the adhesive paste [18]. In order to finish complete transfer, the offset rubber blanket must meet two basic properties: a) it must be conductive; b) must be heated to a temperature above 100 ${ }^{\circ} \mathrm{C}[19]$.

To ensure the ability of the photo quality printing, additional BID's with PANTONE inks need to be added. With this setup prints meet ISO 12647 tone value, and allow the colour gamut volume increase [20]. The second parameter that significantly influences the photo quality is precise (shape and dimension) printing of screen elements (controlled dot gain). Additional quality improvement can be achieved by choice of paper type, while optical component of dot gain depends solely on it [21]. It can be controlled directly by the change of the laser power and by adjusting the ink layer by changing the voltage at BID's units [22-24].

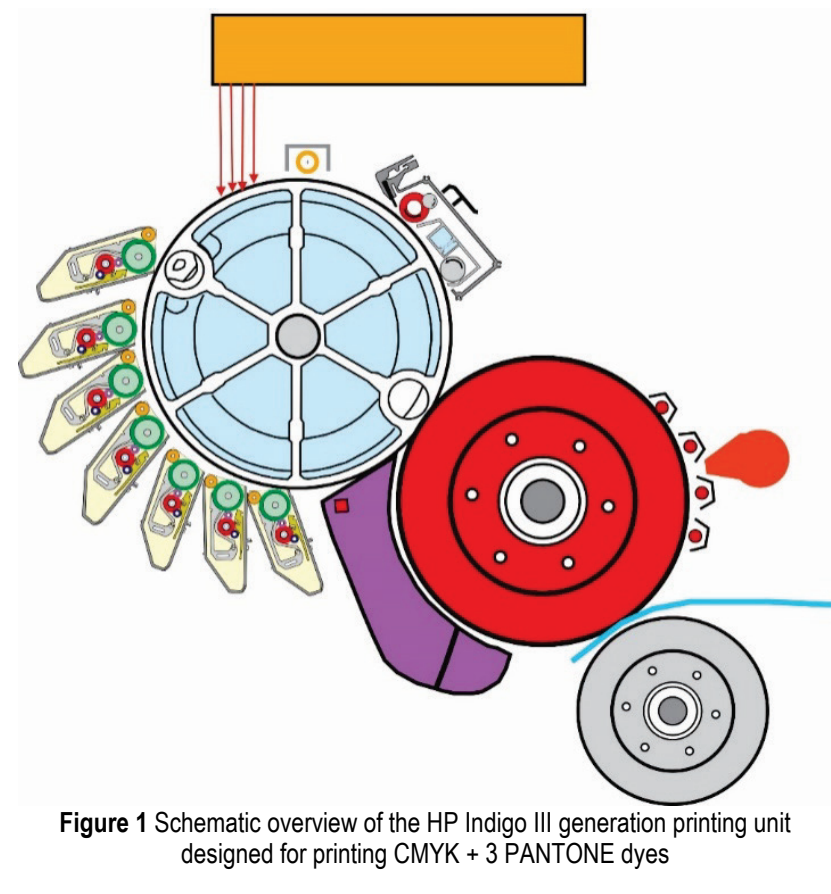

\section{EXPERIMENTAL PART}

For generation of prints in our experiment we use the HP Indigo 7-colour printing machine WS 6800 with an integrated in-line primer and corona unit. ESCO HPE ProLiant ML350 RIP model for colour separation was applied using standard LUT 0.5 calibration curves and 180 lpi. The standard print form "FOGRA Image Quality" of SRA3 was used as a test form and only black separation was studied [9].

The printing substrate in this experiment was $90 \mathrm{~g} / \mathrm{m}^{2}$ Condat digital gloss RL (gloss coated fine art paper). A composition of such paper has 50\% virgin cellulose, $40 \%$ calcium carbonate, $4.5 \%$ water and $5.5 \%$ latex and adhesive [25].
During the printing process paper was treated by means of two different primer depositions (Michem ${ }^{\circledR}$ InLine Primer 030 manufactured by Michelman) in an amount of $0.5 \mathrm{~g} / \mathrm{m}^{2}$ and $1 \mathrm{~g} / \mathrm{m}^{2}$. The corona treatment impact test on the reproductions was also performed. The Vetaphone model VE1A-A (C4) 410 corona unit was used with $450 \mathrm{~W}$ and $950 \mathrm{~W}$ charging power settings.

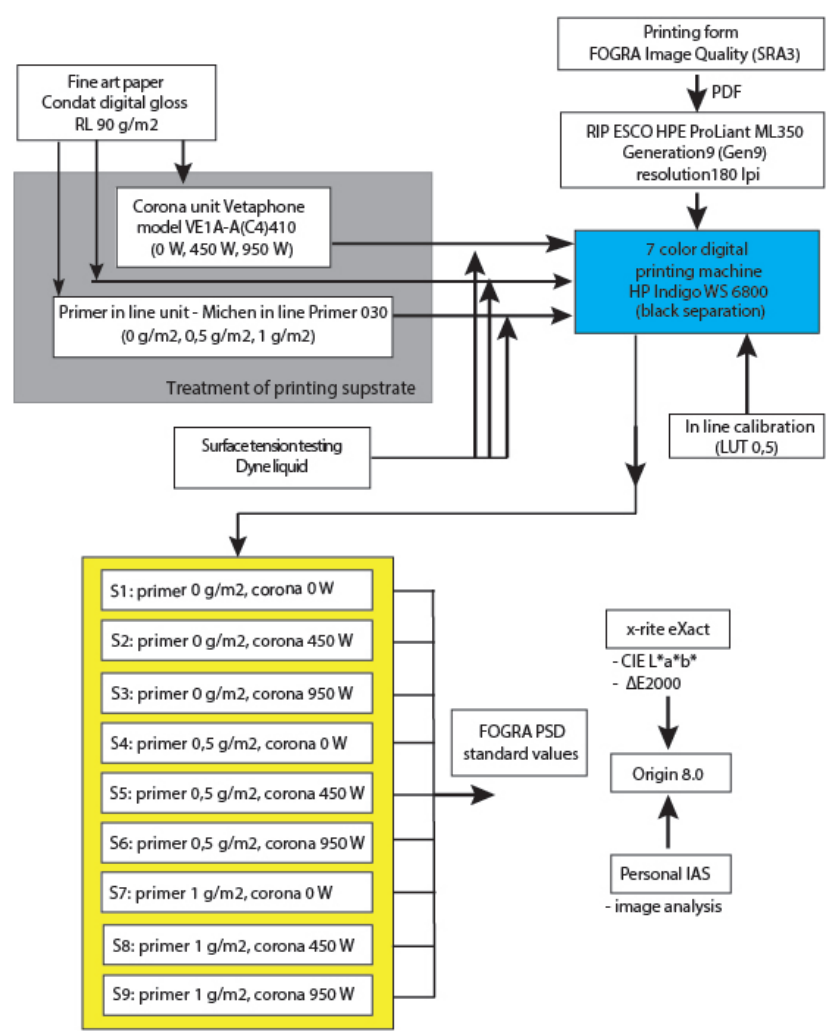

Figure 2 Schematic representation of a chronologically executed experiment

Experimental prints were obtained with several predefined corona voltages $(0 \mathrm{~W}, 450 \mathrm{~W}$ and $950 \mathrm{~W})$ and a different amount of primers applied to the printing substrate: a) untreated surface (without primer); b) surface treated with primer deposit of $0.5 \mathrm{~g} / \mathrm{m}^{2}$ (46 rpm) and c) surface treated with primer deposit of $1 \mathrm{~g} / \mathrm{m}^{2}(96 \mathrm{rpm})$. Thus, combining all above mentioned setups, nine different black samples were obtained (Fig. 2).

To determine the quality of monochromatic reproduction, the 4-generation X-rite eXact colorimeter and spectrophotometer were used [26] while the Personal IAS was used for visual analysis. The obtained CIE $L^{*} a^{*} b^{*}$ and CIE LAB $\triangle E$ results were compared to the existing graphics industry standard ISO 12647-8 [27].

\section{RESULTS AND DISCUSSION}

The graphic technology industry makes extensive use of proofing to predict the rendering of digital data files by a wide variety of high-definition, high-quality off-press printing processes and applications. Each prediction is based on a characterization data set that defines a particular printing condition. In order to reach uniformity of colour reproduction and establish proofing requirements for the most demanding part of the printing and publishing market, we adopt Standard ISO 12647, which recognizes various printing techniques. In Part 8 of this standard are defined reference values for digital printing techniques. 

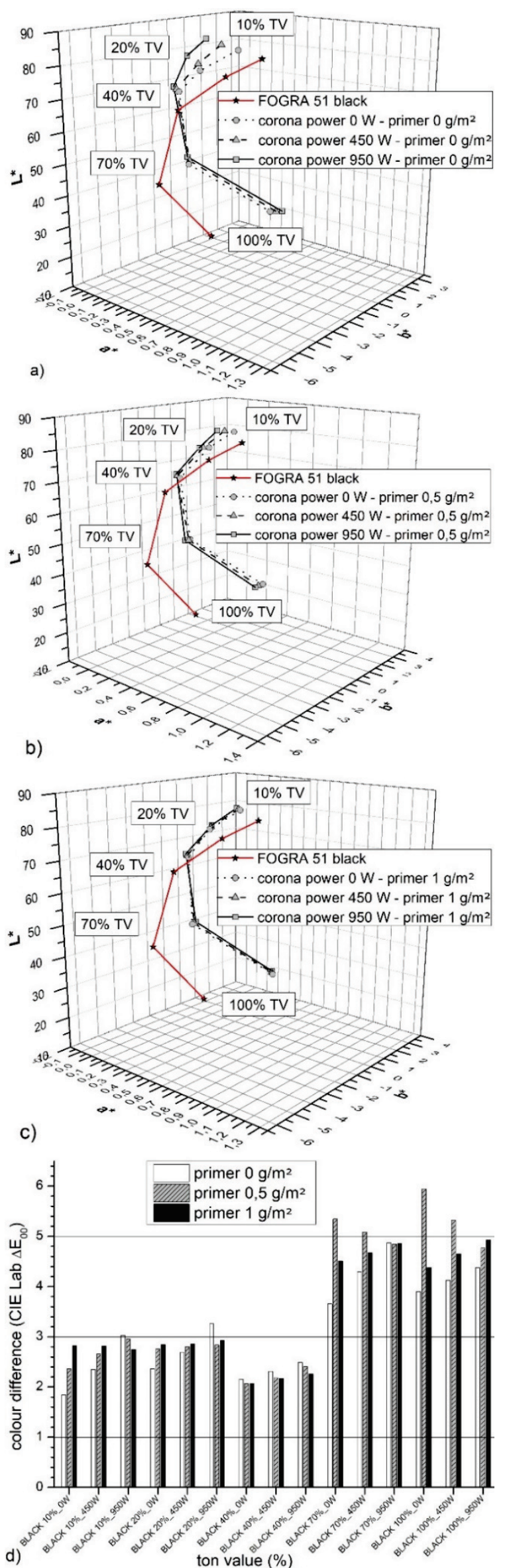

Figure 3 Colour changes of black prints caused by the primer variation and the corona voltage as compared to the FOGRA standard: a) without priming on the voltage of the corona ( $0 \mathrm{~W}, 450 \mathrm{~W}$ and $950 \mathrm{~W})$; b) $0.5 \mathrm{~g} / \mathrm{m}^{2}$ primer on corona voltage ( $0 \mathrm{~W}, 450 \mathrm{~W}$ and $950 \mathrm{~W}) ; \mathrm{c}$ ) a primer of $1 \mathrm{~g} / \mathrm{m}^{2}$ with a voltage of corona $(0 \mathrm{~W}, 450 \mathrm{~W}$ and $950 \mathrm{~W}) ; \mathrm{d}) \Delta E$ colour deviations
A detailed description of the desired colour values is specified by FOGRA PSD, which recommends FOGRA 51 values for art print papers. In order to visualize the measured colour values, CIE LAB $\Delta E$ values are compared with the standard table values of visual perception data. Thus, the colour change $\Delta E<1$ represents visually invisible colour changes, $\Delta E 1$ to 3 colour range within the standard, $\Delta E 3$ to 5 the acceptable colour deviation range and $\Delta E>5$ the unacceptable deviation area. Figs. 3 and 4 show ink colour changes for black prints compared to the printing standard FOGRA 51.

Acrylic black prints exhibit the highest colour oscillations in relation to the FOGRA standard. They are most noticeable in the darkest areas of black images $(70 \%$ and $100 \%$ of TV). The value is especially emphasized by the full tone printed with no corona effect and primer deposition of $0.5 \mathrm{~g} / \mathrm{m}^{2}\left(\Delta E 0 \mathrm{~W}-0.5 \mathrm{~g} / \mathrm{m}^{2}=5.94\right)$. In this case, such prints are not recommended for further usage and need to be corrected by changing the voltage on black BID. Compared to the FOGRA reference, the other ruptured surfaces $(10 \%, 20 \%$ and $40 \%$ of TV) achieve $\Delta E$ colour changes in the area between $\Delta E=2$ and $\Delta E=3$. The minimal $\Delta E$ difference $\left(\Delta E 0 \mathrm{~W}-0 \mathrm{~g} / \mathrm{m}^{2}=1.85\right)$ shows the black print achieved in the $10 \%$ TV without application of primer and corona treatment. Compared to FOGRA, the experimental black prints without application of primer and with variation of applied corona power, deviate on average in amount of $\Delta E=0.82$. Such a difference was generated only by modifying the corona power and is: $\Delta E$ $0 \mathrm{~W}-0 \mathrm{~g} / \mathrm{m}^{2}=2.79 ; \Delta E 450 \mathrm{~W}-0 \mathrm{~g} / \mathrm{m}^{2}=3.16 ; \Delta E 950 \mathrm{~W}$ - $0 \mathrm{~g} / \mathrm{m}^{2}=3.61$. Additional prints stabilization can be achieved by applying primer. The toner nanoparticle of 0.5 $\mathrm{g} / \mathrm{m} 2$ yield the highest colour change in relation to the standard: $\left(\Delta E 0 \mathrm{~W}-0.5 \mathrm{~g} / \mathrm{m}^{2}=3.70 ; \Delta E 450 \mathrm{~W}-0.5 \mathrm{~g} / \mathrm{m}^{2}\right.$ $\left.=3.61 ; \Delta E 950 \mathrm{~W}-0 \mathrm{~g} / \mathrm{m}^{2}=3.56\right)$. An additional increase in the amount of primer on the printing substrate will have a slight reduction in colour change, which is economically unprofitable $\left(\Delta E 0 \mathrm{~W}-1 \mathrm{~g} / \mathrm{m}^{2}=3.33 ; \Delta E 450 \mathrm{~W}-1 \mathrm{~g} / \mathrm{m}^{2}\right.$ $\left.=3.43 ; \Delta E 950 \mathrm{~W}-1 \mathrm{~g} / \mathrm{m}^{2}=3.54\right)$. Overall experimentally obtained colour changes in black tones result in average of $\Delta E=0.91$.

In order to visualize realized $\Delta E$ changes of achromatic tones, experimental prints have been digitized and magnified 60 times (Fig. 4).

With colorimetric and visual estimation of magnified images, it is obvious that solid black tones prints are realized without the application of primer and corona treatment. It means that black ElectroInk in this condition is closest to the ideal achromatic axis. We can notice that ideal black half tone can be achieved by activation corona power of $950 \mathrm{~W}$. The smallest printing elements (dots) on prints have the highest sharpness, equal saturation and appropriate circularity. In our experiment that produces the best achromatic reproduction. 

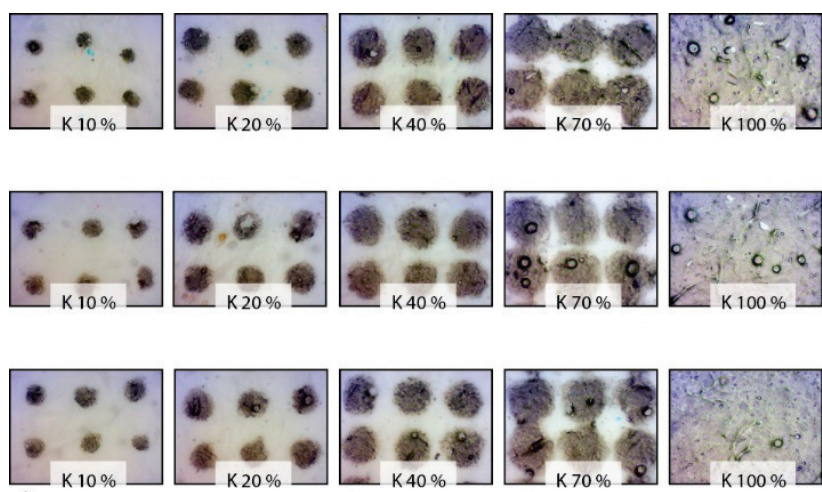

a)
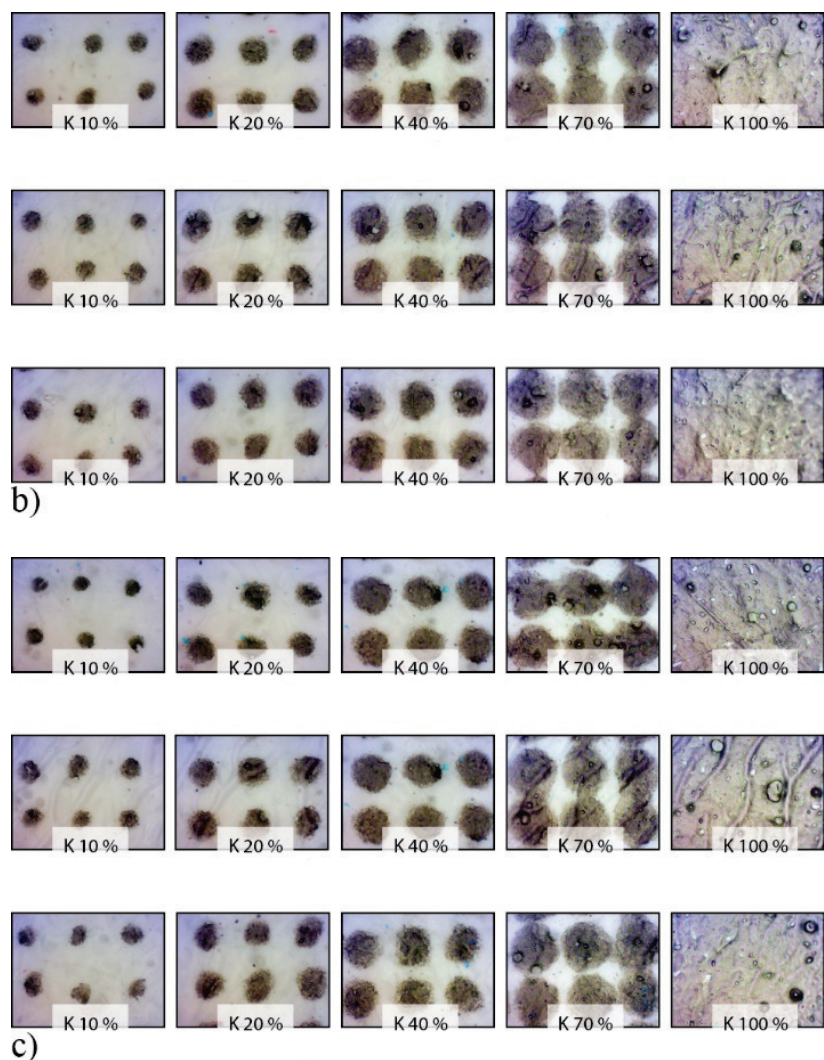

)

4 Magnified HP Indigo prints: a) without priming and applied corona voltage ( $0 \mathrm{~W}, 450 \mathrm{~W}$ and $950 \mathrm{~W}) ; \mathrm{b}) 0.5 \mathrm{~g} / \mathrm{m}^{2}$ primer at corona voltage $(0 \mathrm{~W}, 450$ $\mathrm{W}$ and $950 \mathrm{~W}) ; \mathrm{c})$ a primer of $1 \mathrm{~g} / \mathrm{m}^{2}$ at corona voltage $(0 \mathrm{~W}, 450 \mathrm{~W}$ and $950 \mathrm{~W})$

\section{CONCLUSION}

Minimum tone deviation in black prints will occur without application of primer and corona treatment in regards to FOGRA 51 standard. Such a black colour difference for all analysed tones (average value) will be visible to human eye $\Delta E=2.79$. Minimum tone deviation for black prints is $\Delta E=3.70$. These prints were realized with application of primer in amount of $0.5 \mathrm{~g} / \mathrm{m}^{2}$ and without the activation of corona unit. Relatively small black colour deviation of the black separation $(\Delta E=0.91)$ was achieved by above mentioned experimental set ups. This deviation is not visible for human eye. But with its value and combination with other manufacturing printing parameters (type of paper, ink pigmentation, develop voltage, laser power, ...) it contributes to the formation of optimal black tone prints.

\section{REFERENCES}

[1] Smyth, S. (2017). The Future of Global Printing to 2022. Leatherhead, UK.

[2] Wang, Y. (2016). The Adoption of Next Generation Digital Printing Technology in Package Printing. Rochester Institute of Technology.

[3] Landolt, K. (2007). Development of test targets for microprinting applications on the Kodak Nexpress 2100 , the Hewlett packard Indigo 5000 and the Heidelberg Speedmaster 74. Rochester Institute of Technology.

[4] Hoffstadt, H. (2016). How to Create Characterization Data for a Printing Standard. TAGA, 12-14.

[5] Rong, X. (2008). G7 Method for Indigo Press Calibration and Proofing. NIP24 and Digital Fabrication, 603-606.

[6] Tsigonias, A., Gamprellis, G., Politis, A. \& Tsigonias, M. (2014). Hexachrome system modification for a prototype screenprinting. GRID 2014.

[7] Howard, B. A. (2012). Accurately Reproducing Pantone Colors on Digital Presses. California Polytechnic State University.

[8] Staelin, C. (2011). Electro-photographic model based stochastic clustered-dot halftoning with direct binary search. International Conference on Image Processing, 2011, 4.

[9] Kraushaar, A. (2018). Process Standard Digital Handbook. Munich: Fogra Research Institute for Media Technologies.

[10] Majnarić, I. (2016). Osnove digitalnog tiska. Zagreb, Hrvatska: Sveučilište u Zagrebu Grafički fakultet.

[11] Forgacs, P. (2013). Theory of Ink Transfer in HP-Indigo Digital Press Machines. NIP 29 Digit. Fabr. 2013, 429-433.

[12] Mosenson, N. (2014). Digital Print Entering B2 Format: Challenges \& Solutions. TAGA 2014, 236-243.

[13] Indigo, H. (2016). The world of HP ElectroInks. HP Indigo Prospect. Retrieved from https://vdocuments.mx/the-worldof-hp-indigo-world-of-hp-indigo-electroinks-the-exclusivecapabilities.html.

[14] Benzion, L. et al. (1988). Toner for Use in Compositions for Developing Latent Electrostatic Images, Method of Making the Same, and Liquid Composition Using the Improved toner, 18.

[15] Yaacov, A. (1991). Humidity Tolerant Charge Director Compositions, 6.

[16] Forgacs, P. \& Teishev, A. (2013). Electro-Rheological Model of HP Indigo ElectroInk. J. Imaging Sci. Technol., 56(4), 1-9. https://doi.org/10.2352/J.ImagingSci.Technol.2013.57.3.030403

[17] Majnaric, I., Golubovic, K., Bolanca, S. \& Modric, D. (2011). Voltage Effect on Developing Process and B\&W Reproduction. DAAAM Int. Sci. B. 2010. https://doi.org/10.2507/daaam.scibook.2010.45

[18] Majnarić, I., Bolanča, I., Bolanča, Z., \& Milković, M. (2005). Conditions in digital printing of packaging on the print quality. International Conference on Digital Production Printing and Industrial Applications, DPP2005 - Final Program and Proceedings, (2005).

[19] Gazit, A. (1998). Imaging Apparatus And Intermediate Transfer Blanket Therefor, 20.

[20] Tagansky, B. (2012). HP-Indigo Technology and its Application to Photo Printing. NIP28: The 28th International Conference on Digital Printing Technologies and Digital Fabrication 2012, 31-34. https://doi.org/10.2352/ISSN.2169-4672.2012.3.0.7

[21] Itrić, K., Modrić, D., \& Milković, M. (2018). Edge spread function for the paper-ink system. Nord. Pulp Pap. Res. J., 33(3), 542-547. https://doi.org/10.1515/npprj-2018-3054

[22] Majnaric, I., Modric, D., \& Golubovic, K. (2008). Influence of laser power output on the quality of colour imaging. Annals of DAAAM and Proceedings of the International DAAAM Symposium.

[23] Majnaric, I., Bolanca, Z., \& Bolanca Mirkovic, I. (2009). 
The influence of the developer drum voltage on screen dot formation. Annals of DAAAM and Proceedings of the International DAAAM Symposium.

[24] Majnarić, I., Hladnik, A., Muck, T., \& Mirković, I. B. (2015). The influence of ink concentration and layer thickness on yellow colour reproduction in liquid electrophotography toner. Tehnički Vjesnik, 22(1), 145-150. https://doi.org/10.17559/TV-20140321230455

[25] Lecta group. Condat data sheet (2018). Retrieved from https://cmspro.lecta.com/Digital/LectaProductCertificates/S afetyDataSheet_Condat.pdf

[26] X-rite, x-rite eXact Spectrophotometer (2018). Retrieved from https://www.xrite.com/categories/portable -spectrophotometers/exact

[27] ISO 12647-8:2012 Graphic technology -- Process control for the production of half-tone colour separations, proof and production prints -- Part 8: Validation print processes working directly from digital data. International Organization for Standardization, 2012. Retrieved from https://www.iso.org/standard/53436.html.

\section{Contact information:}

\section{Marko MORIĆ, MSc}

(Corresponding author)

University Nord, Multimedia, Design and Application,

Jurja Križanića 31b, 42000 Varaždin, Croatia

E-mail:mmoric@unin.hr

Igor MAJNARIĆ, Assoc. Prof

University of Zagreb, Faculty of Graphic Arts,

Getaldićeva 2, 10000 Zagreb, Croatia

E-mail: igor.majnaric@grf.hr

Damir MODRIĆ, Assoc. Prof

University of Zagreb, Faculty of Graphic Arts,

Getaldićeva 2, 10000 Zagreb, Croatia

E-mail: damir.modric@grf.hr 